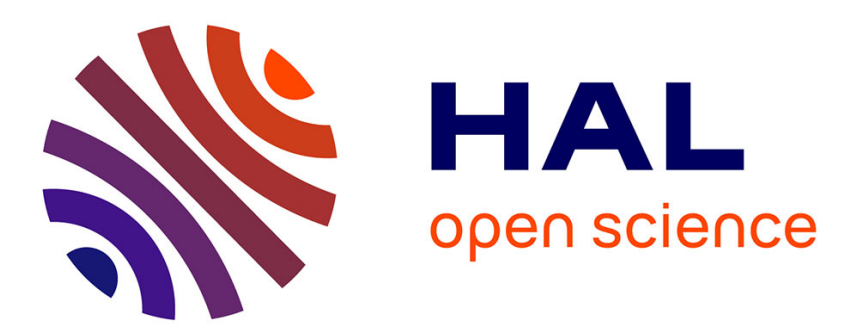

\title{
An experimental study of the effects of surface roughness on the laminar-turbulent transition of a $2 \mathrm{D}$ incompressible boundary-layer
}

Felix Ducaffy, Maxime Forte, Olivier Vermeersch, Estelle Piot

\section{- To cite this version:}

Felix Ducaffy, Maxime Forte, Olivier Vermeersch, Estelle Piot. An experimental study of the effects of surface roughness on the laminar-turbulent transition of a 2D incompressible boundary-layer. AIAA Scitech 2021 Forum, Jan 2021, Virtual event, United States. pp.AIAA 2021-0247, 10.2514/6.20210247 . hal-03417162

\author{
HAL Id: hal-03417162 \\ https://hal.science/hal-03417162
}

Submitted on 5 Nov 2021

HAL is a multi-disciplinary open access archive for the deposit and dissemination of scientific research documents, whether they are published or not. The documents may come from teaching and research institutions in France or abroad, or from public or private research centers.
L'archive ouverte pluridisciplinaire HAL, est destinée au dépôt et à la diffusion de documents scientifiques de niveau recherche, publiés ou non, émanant des établissements d'enseignement et de recherche français ou étrangers, des laboratoires publics ou privés. 


\title{
An experimental study of the effects of surface roughness on the laminar-turbulent transition of a $2 \mathrm{D}$ incompressible boundary-layer
}

\author{
Ducaffy Félix*, Forte Maxime ${ }^{\dagger}$, Vermeersch Olivier ${ }^{\star}$ and Piot Estelle ${ }^{\S}$ \\ ONERA/DMPE, Université de Toulouse, 31055 Toulouse, France
}

\begin{abstract}
While it is well known that increasing surface roughness tends to shift the transition location of a boundary-layer upstream, no model is currently able to accurately predict this shift as a function of the roughness parameters (mean roughness, skewness, etc.) for a transition driven by Tollmen-Schlichting instabilities. Moreover, the physics involved in this phenomenon is not well understood. Using a flat plate equipped with three exchangeable inserts whose roughness can be adjusted by 3D printing, experimental data are collected for different roughness values, different streamwise locations and different Reynolds numbers. The cases with rough inserts are systematically compared to the smooth reference cases and the Linear Stability Theory is used to estimate $\Delta N$ values as a function of roughness parameters. These data constitute a first step towards a larger database which will make it possible to create a $\Delta N$ model for the prediction of this effect. Hypotheses about the physical phenomena involved (changes in amplification and/or receptivity process) are proposed using the collected data.
\end{abstract}

\section{Nomenclature}

A. Roman letters

$x=$ streamwise location, $\mathrm{x}=0$ is the leading edge of the flat plate

$y \quad=$ wall normal location, $\mathrm{y}=0$ is the surface of the flat plate

$U=$ Streamwise (x) component of velocity

$u^{\prime}=$ root mean square value of the streamwise (x) component of velocity fluctuation

$R_{e} \quad=$ unit Reynolds number

$C_{p}=$ Pressure coefficient

$N=$ Amplification factor

$T_{u}=$ Turbulence level $\left(T_{u}=u^{\prime} / U\right)$

$R_{a}=$ Roughness mean height

$R_{q}=$ Root mean square of the roughness heights

$R_{s k}=$ Roughness skewness

$R_{k u}=$ Roughness kurtosis

\section{B. Greek letters}

$\delta_{1}=$ Displacement thickness

$\theta=$ Momentum thickness

$\beta=$ Angle between the flat plate and the trailing edge flap

$v=$ Kinematic viscosity

\footnotetext{
*PhD student, felix.ducaffy@onera.fr

†Dr-engineer, maxime.forte@onera.fr

†Dr-engineer, olivier.vermeersch@onera.fr

§Dr-engineer, estelle.piot@onera.fr
} 


\section{Subscripts}

$0=$ Freestream

$T=$ Transition location

\section{Introduction}

$\mathrm{T}$ He need to reduce aviation's carbon emissions has sparked great interest in researches about laminar wing. To design laminar flow wings, it is necessary to have a good understanding of the different paths to laminar-turbulent transition and of the different factors which can influence the transition for each of these paths. For a "low" level of turbulence like in cruise flight, Morkovin [1] found that the transition results from the amplification of eigenmodes such as Tollmien-Schlichting (TS) waves or crossflow instabilities. For an incompressible 2D flow, there is no crossflow waves, and according to Squire [2] the transition will be driven by 2D TS waves since for every 3D TS mode unstable at a given Reynolds number, there is a 2D mode less stable at a lower Reynolds number. The transition of the boundary-layer in this paper will always be driven by this scenario.

Several factors such as free-stream turbulence or surface defaults are known to influence the laminar-turbulent transition of a boundary layer by increasing the receptivity process or the amplification of these TS instabilities. Of the three types of surface imperfections (2D defaults like steps or gaps, 3D isolated roughness like holes or humps and surface roughness), the surface roughness effect on the transition may be the least understood. Indeed, as reviewed by Arnal [3], there are models to take into account the effect of 2D defaults or 3D isolated roughness, but there is no equivalent for surface roughness. This roughness can have different origins: icing on a wing or high temperature and sand on a blade for example. Corke et al [4] found that the average roughness of commercial engine blades was around $85 \mu \mathrm{m}$ and can rise up to $160 \mu \mathrm{m}$ for military engines.

For a 3D isolated roughness, it has been found that there is a critical height of roughness above which the transition starts nearly immediately after the roughness and under which it has nearly no effect on the transition location (Von Doenhoff and Braslow [5]). Braslow and Knox [6] gave a simplified method to calculate this height. An experiment made by Von Doenhoff and Horton [7] using a distributed roughness with low density (carborundum grains covering from 5 to 10 percent of the surface) on a small part of a wing showed the same effect. But for more dense surface roughness, several studies found out there seems to be a cumulative effect of subcritical roughness on the TS waves and that the transition location may be affected. Jeong et al [8] clearly showed that increasing the average roughness tends to shift the transition upstream but found no distortion of the boundary layer profile due to roughness in the laminar zone. Roberts and Yaras [9] studied the effect of different parameters and showed a potential effect of the skewness and the average spacing for a constant average roughness on the transition location.

Despite the improvement of the technical means making it possible to characterize the roughness and its effect on the boundary layer, no model is currently able to describe precisely the effect of the surface roughness parameters (height and shape values, length, etc.) on the transition. Attempts have been made on other transition paths, such as Crouch's [10] [11] who modelled a variable critical $\mathrm{N}$-factor, the value of which decreases logarithmically with the root mean square value of the roughness height for a transition driven by crossflow instabilities.

The goal of this paper is to provide information about the influence of the surface roughness on the TollmienSchlichting instabilities by collecting experimental data on a flat plate machined to receive three exchangeable inserts 3D printed with a rough surface, coupled with numerical investigations of the linear stability of the boundary layer over this plate. This experiment is carried out in order to have a better understanding of the physics involved and to link the evolution of critical $\mathrm{N}$-factor $N_{T}$ with the roughness parameters.

The present paper is organized as follow: the experimental setup and the methodology are first described in sections [III and IV] Then, the validation of the reference 'smooth' case is presented in section $\mathrm{V}]$ Eventually, the results obtained during the experiments with roughness are presented and discussed in the section VI

\section{Experimental setup}

\section{A. Experimental facility}

This experiment was conducted in the subsonic open-return TRIN 1 wind tunnel located at the research facilities of ONERA Toulouse. It features a low turbulence level $0.5 \times 10^{-3}<\mathrm{Tu}<2 \times 10^{-3}$ in the $[3 \mathrm{~Hz}, 11.3 \mathrm{kHz}]$ range depending 
on the free-stream velocity, which ranges from 5 to $80 \mathrm{~m} / \mathrm{s}$. This facility operates at ambient conditions and is well suited for transition experiments. Freestream velocity and unit Reynolds number are determined with a Pitot-static tube and a total temperature probe located at the test section entrance.

As illustrated in the figures 1 and 2, a flat plate (1200 mm long, $600 \mathrm{~mm}$ large and $38 \mathrm{~mm}$ thick) made of aluminium with a specific recess for three exchangeable inserts, is mounted horizontally in the wind tunnel. This plate has a leading edge shape that was numerically optimized to minimize any suction peak on the upper side where measurements are acquired, as for the plate described in [12] which has the same shape. The lower side is semi-elliptical while the upper side is defined by a third-order Béziers polynomial. At the trailing edge, there is a flap whose angle $(\beta)$ can be modified to change the pressure gradient at the leading edge and the location of the natural transition. For this experiment, the angle is always $\beta=0^{\circ}$ to minimize the suction peak. The resulting Cp distributions for the different Reynolds numbers tested are shown figure 3 All tests in the experiments were performed between $\operatorname{Re}=1.910^{6} \mathrm{~m}^{-1}$ and $\operatorname{Re}=4.310^{6} \mathrm{~m}^{-1}$ ( corresponding to approximate velocity values of $29 \mathrm{~m} / \mathrm{s}$ and $64 \mathrm{~m} / \mathrm{s}$ ).

The exchangeable inserts are used to change the surface roughness of the flat plate. They can be either smooth (metal machined) or rough (3D printed with Peopoly - Phenom 3D printer). They are designed using Cassiopee (ONERA's in-house code based on Python) and the generated STL files are then sent to the 3D printer via the software Chitubox. An exemple of STL file is shown in figure 4

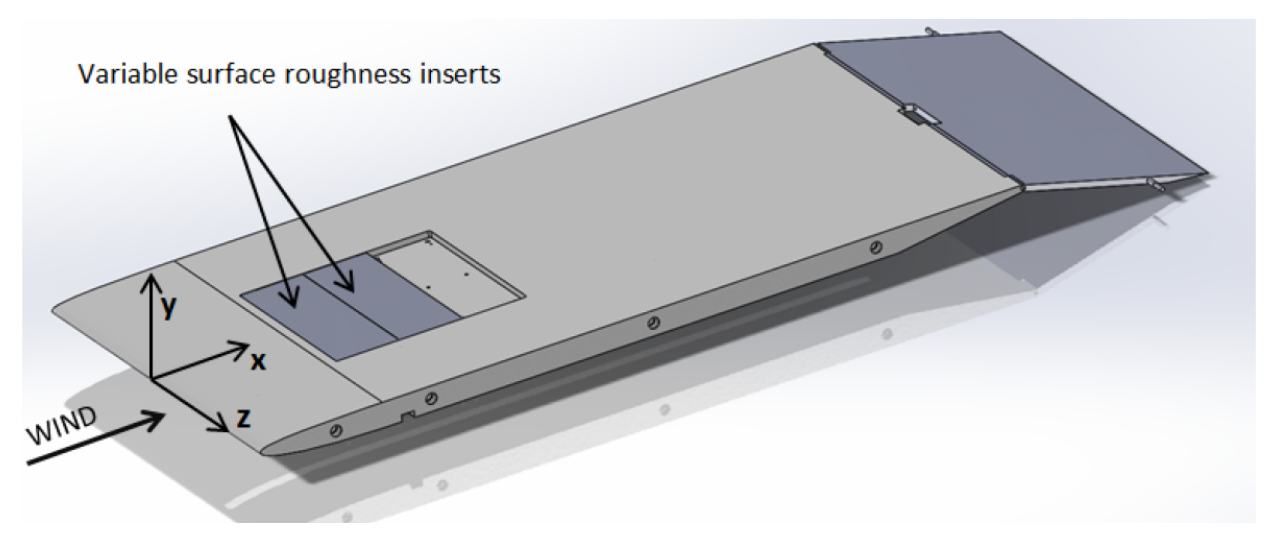

Fig. 1 Flat plate used in this experiment

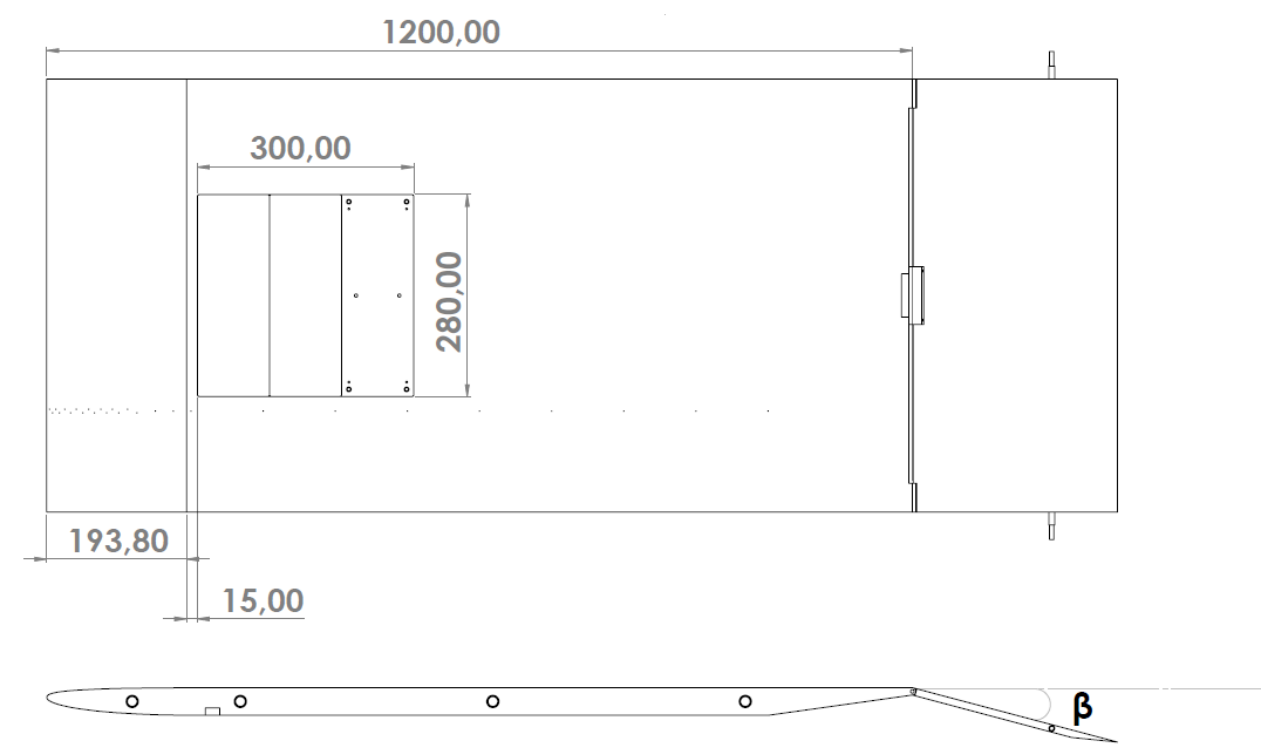

Fig. 2 Drawing of the flat plate machined to receive three exchangeable inserts 


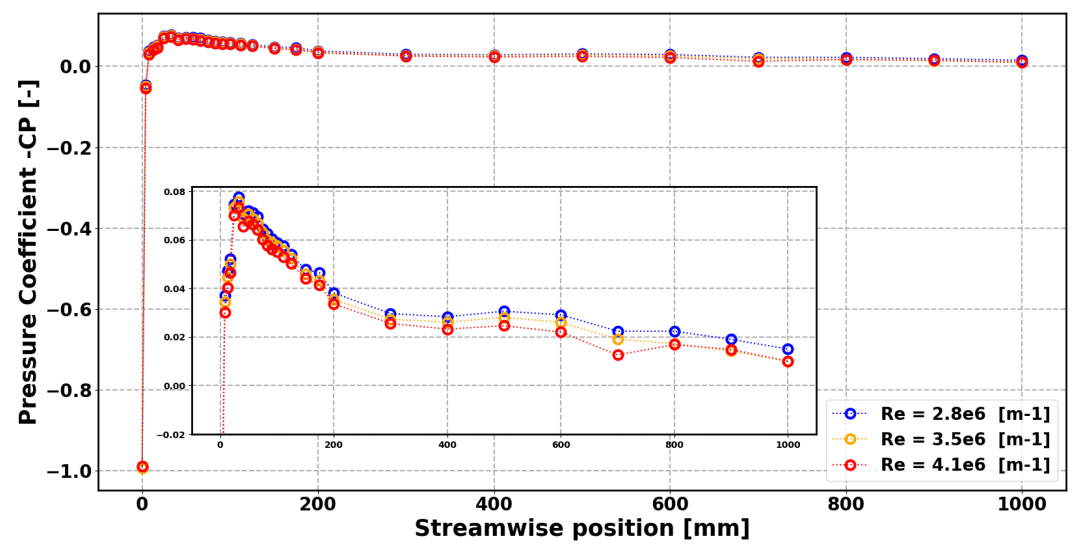

Fig. 3 Resulting pressure distributions along our flat plate for the different unit Reynolds numbers tested

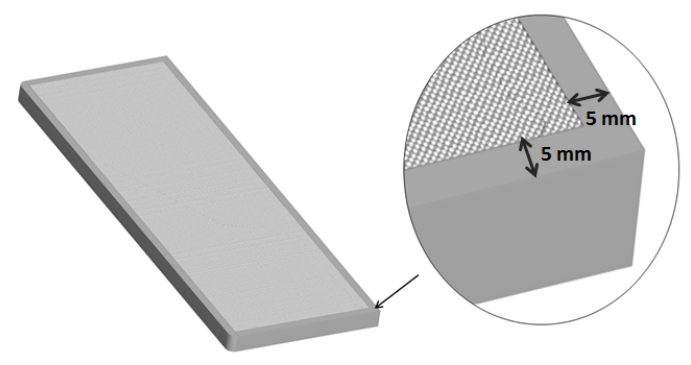

Fig. 4 Example of numerical model for 3D printing

\section{B. Instrumentation and data acquisition}

Static pressure ports are distributed along the entire length of the flat plate. Pressure measurements are made using two SVMtec PSC24-USB differential pressure scanners providing 24 channels ranging $+/-2.5 \mathrm{kPa}$ and 24 ranging $+/-5$ $\mathrm{kPa}$. The dynamic pressure from the Pitot-static tube and the difference of pressure between atmosphere and test section are measured using two MKS Baratron type 220D ranging +/- $10 \mathrm{kPa}$. Velocity measurements are acquired using a hot-wire probe mounted on a 3D traverse motioned by stepping motors driven by an ESP300 Newport motion controller. Boundary layer investigations are made using hot-wire anemometry (Dantec Streamline, 90C10 CTA module and 55P15 probe for boundary layer exploration). For each data point, 250000 samples are acquired at $25 \mathrm{kHz}$. The data are collected using National Instruments Compact DAQ-9178 with NI-9215 (16 bits card, for pressure and temperature measurements), NI-9239 with anti-aliasing filter included (24 bits card for hot-wire measurements) and NI-9211 (for thermocouple) cards.

Several solutions can be used to determine the transition location using the hot wire's signal. The chosen method [12] consists in determining the transition location thanks to the slope of the curve of $\frac{\mathrm{u}}{\mathrm{U}_{0}}$ against the abscissa. A data point is considered to be the beginning of the transition if the slope is higher than $2.10^{-4}\left[\mathrm{~mm}^{-1}\right]$ and stays positive for at least $100 \mathrm{~mm}$.

The statistical roughness data of the printed surfaces are acquired using a Gocator 2320 which enables height measurements along a laser line long of $2.6 \mathrm{~cm}$. Vertical resolution of this device is $2 \mu \mathrm{m}$ and horizontal is from $14 \mu \mathrm{m}$ at center of the line to $21 \mu \mathrm{m}$ at the edges. During the roughness measurements, the Gocator 2320 is connected to a Posimag PMIS3 sensor which moves along an aluminium structure. While moving, the PMIS3 sensor sends a trigger to the Gocator 2320 to make a measurement every $100 \mu \mathrm{m}$ (the first measurements were made with a sample every $10 \mu \mathrm{m}$ but no difference were observed when comparing with measurements every $100 \mu \mathrm{m}$ ). A great number of measurements (at least 300 for each sample) can thus be performed on a surface to get reliable statistical data. 


\section{Roughness parameters}

There is not a single parameter able to describe all the features of a surface. Rather, it is necessary to use a set of different parameters, each one describing a single characteristic of a surface. Most of these parameters are calculated using a "mean line" of roughness, shown in figure 5 .

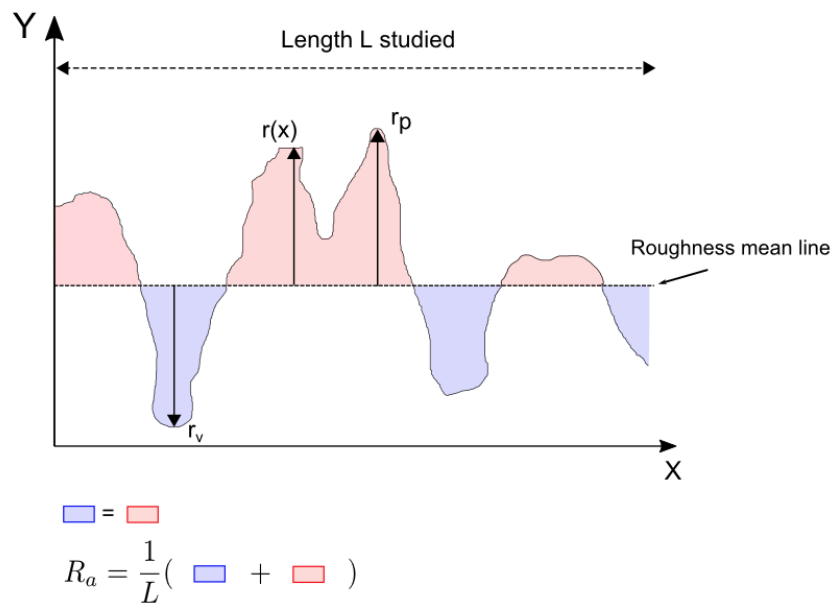

Fig. 5 Mean line and some roughness features

\section{Mean roughness $(\mathrm{Ra})$}

Mean roughness $R a$ is the mean distance with mean line:

$$
R_{a}=\frac{1}{L} \int_{0}^{L}|r(x)| \mathrm{d} x
$$

It can be calculated from acquired data using the following definition:

$$
R_{a}=\frac{1}{N} \sum_{i=1}^{N}\left|r_{i}\right|
$$

\section{Root mean square - $R q$}

Root mean square value $R q$ is the standard deviation of the pikes and valleys heights. $\mathrm{Rq}$ is correlated with $\mathrm{Ra}$ :

$$
R_{q}=\sqrt{\frac{1}{L} \int_{0}^{L} r^{2}(x) \mathrm{d} x}
$$

The discretized expression is the following:

$$
R_{q}=\sqrt{\frac{1}{N} \sum_{i=1}^{N} r_{i}^{2}}
$$

The other roughness parameters and the way they are calculated are presented in appendix VII.A

\section{Methodology}

The results presented in section VI come from experiments performed with inserts having the same surface roughness but tested in three different positions as presented in figure 6. The roughnesses on the surface of these inserts are 
designed as smoothed squares, $1 \mathrm{~mm}$ long and large and $200 \mu \mathrm{m}$ high, with the middle height aligned with the smooth edge. For each case, streamwise and spanwise investigations were first made to find the transition location and check the bidimensionality. Then, several boundary layers profiles were measured for different locations (above and behind the rough part) and for different unit Reynolds numbers. The exact locations of the roughness for each case are indicated in table 2 As described in the following section $\mathrm{V}$, critical $\mathrm{N}$-factor $\left(N_{T}\right)$ are determined using the combination of ONERA's in-house code for LST and experimental results.

\begin{tabular}{|c|c|c|c|c|}
\hline Position of the insert & $\mathrm{Ra}[\mu \mathrm{m}]$ & $\mathrm{Rq}[\mu \mathrm{m}]$ & $\mathrm{R}_{\mathrm{sk}}[-]$ & $\mathrm{R}_{\mathrm{ku}}[-]$ \\
\hline Position 1 & 61 & 70 & 0.058 & 1.88 \\
\hline Position 2 & 57 & 65 & 0.072 & 1.91 \\
\hline Position 3 & 59 & 67 & 0.038 & 1.89 \\
\hline
\end{tabular}

Table 1 Roughness parameters of the tested inserts

\begin{tabular}{|c|c|c|}
\hline Position of the insert & Roughness upstream edge [mm] & Roughness downstream edge [mm] \\
\hline Position 1 & 213.8 & 303.8 \\
\hline Position 2 & 313.8 & 403.8 \\
\hline Position 3 & 413.8 & 503.8 \\
\hline
\end{tabular}

Table 2 Exact streamwise locations of the rough surfaces for the three positions tested

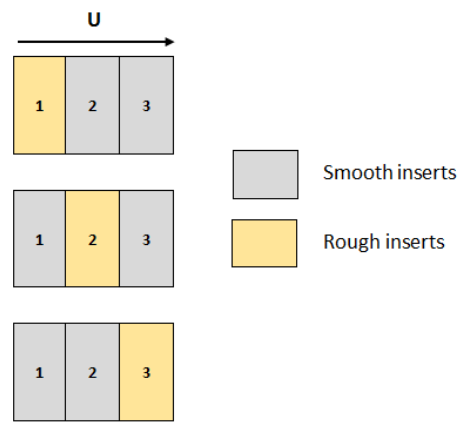

Fig. 6 Scheme of experiments to study the influence of the position of the roughness

\section{Validation of the reference case}

In order to validate the reference 'smooth' case, ONERA's in-house codes 3C3D (boundary layer code) and CASTET (local linear stability theory (LST) solver) were applied to the pressure distributions acquired on the flat plate for three different unit Reynolds numbers $\left(2.8,3.5\right.$ and $\left.4.110^{6} \mathrm{~m}^{-1}\right)$. First of all, comparisons between numerical and experimental results were performed to get sure the boundary layer evolves along the flat plate as predicted by the boundary layer equations. With an example of a boundary layer profile and boundary layer parameters, figure 7 shows a good agreement between experimental results and numerical calculations.

The wall normal evolutions of the fluctuating velocity $\mathrm{u}^{\prime}$ between numerical and experimental data were compared for a particular TS mode at a given location. To do so, measurements were made at $\operatorname{Re}=3.5 \times 10^{6} \mathrm{~m}^{-1}$ and $\mathrm{x}=870$ $\mathrm{mm}$ which is really close to the transition point. The power spectral densities (PSD) of u' are shown in figure 8 , The typical signal of TS waves around $750 \mathrm{~Hz}$ is observed, showing this is the most amplified frequency for this case. This is close to the value found by the stability computations (see figure 9). Then, this PSD was integrated in the frequency range $730-770 \mathrm{~Hz}$ for each point of the wall-normal boundary layer exploration. The resulting experimental fluctuations 


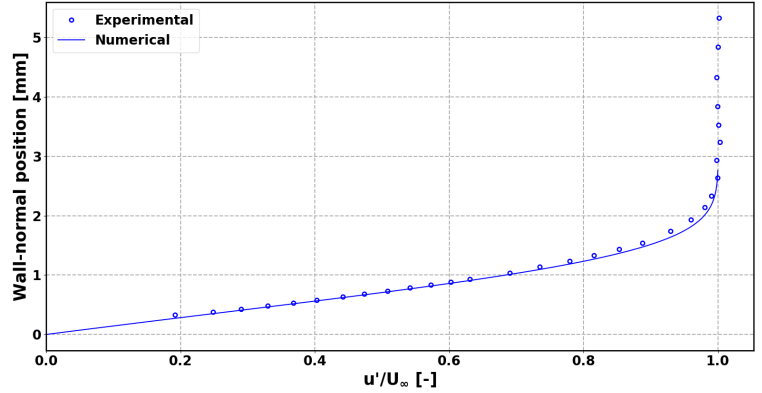

(a) Boundary layer at $x=700 \mathrm{~mm}$

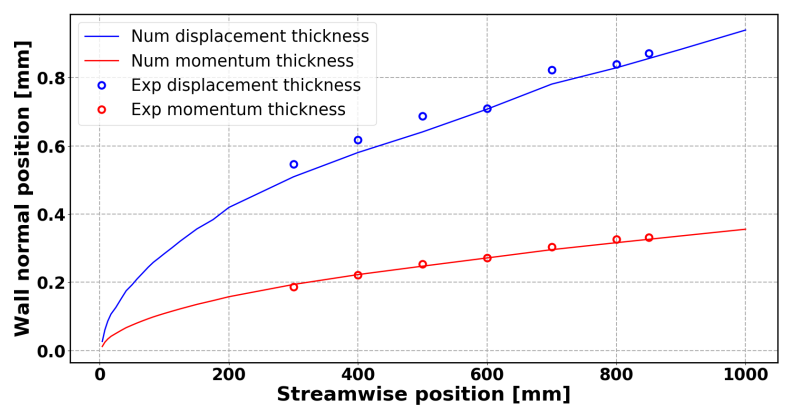

(b) Displacement and momentum thicknesses

Fig. 7 Comparisons of the numerical and experimental boundary layers at $\operatorname{Re}=3.5 * 10^{6} \mathrm{~m}^{-1}$

profile is compared to the numerical TS mode at $\mathrm{f}=750 \mathrm{~Hz}$ from the LST (see figure 10). There is not a perfect agreement but the global shape of the TS mode can be observed and confirms the transition is driven by TS waves.

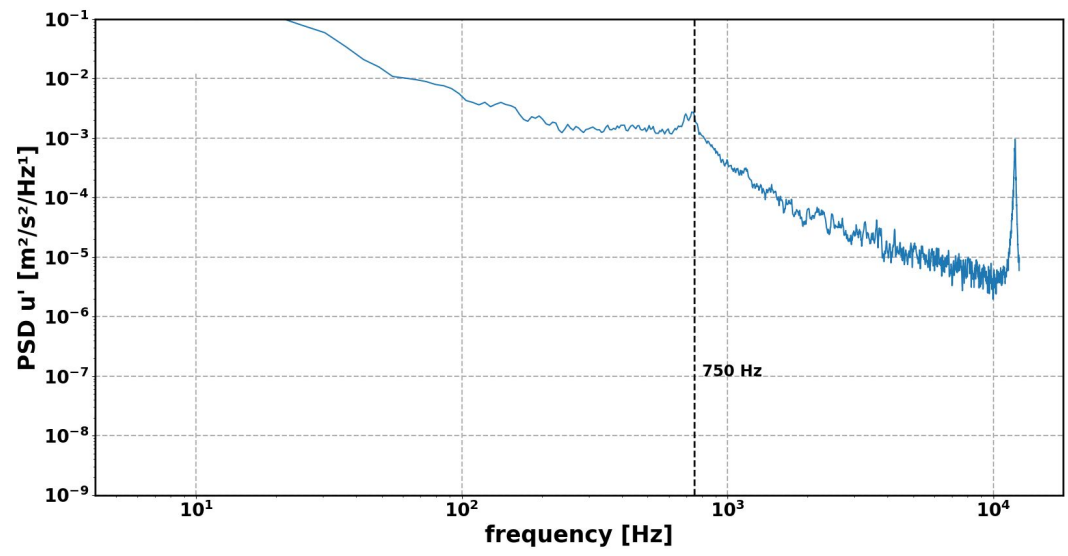

Fig. 8 PSD of $u^{\prime}$ at $\operatorname{Re}=3.5 * 10^{6} \mathrm{~m}^{-1}$ for $x=870 \mathrm{~mm}$ and $\mathrm{y}=600 \mu \mathrm{m}$

Eventually, streamwise velocity measurements were performed in order to locate the transition onset as shown in figure 11. The reference smooth case is summed up in the table 3 . For every Reynolds number tested several parameters are displayed: $x_{T}$ (transition abscissa), $R e_{x_{T}}$ (Reynolds number based on transition abscissa), $N_{T}$ (critical N-factor), $F_{\text {exp }}$ (frequency of the most amplified TS wave measured just upstream of the transition location) and $F_{L S T}$ (frequency of the most amplified TS wave at the transition location according to LST). The values presented in this table are used as references to compare with to discuss the influence of the surface roughness.

\begin{tabular}{|c|c|c|c|c|c|}
\hline$R e\left(\mathrm{x} 10^{-6}\right)$ & $x_{T}[\mathrm{~mm}]$ & $\operatorname{Re}_{x_{T}}\left(\mathrm{x} \mathrm{10^{-6 }}\right)$ & $N_{T}$ & $F_{\exp }[\mathrm{Hz}]$ & $F_{L S T}[\mathrm{~Hz}]$ \\
\hline 2.8 & 1070 & 3.00 & 10.3 & 500 & 500 \\
\hline 3.5 & 870 & 3.04 & 10.5 & 750 & 850 \\
\hline 4.1 & 710 & 2.91 & 10.4 & 1150 & 1150 \\
\hline
\end{tabular}

Table 3 Summary of the reference smooth case 


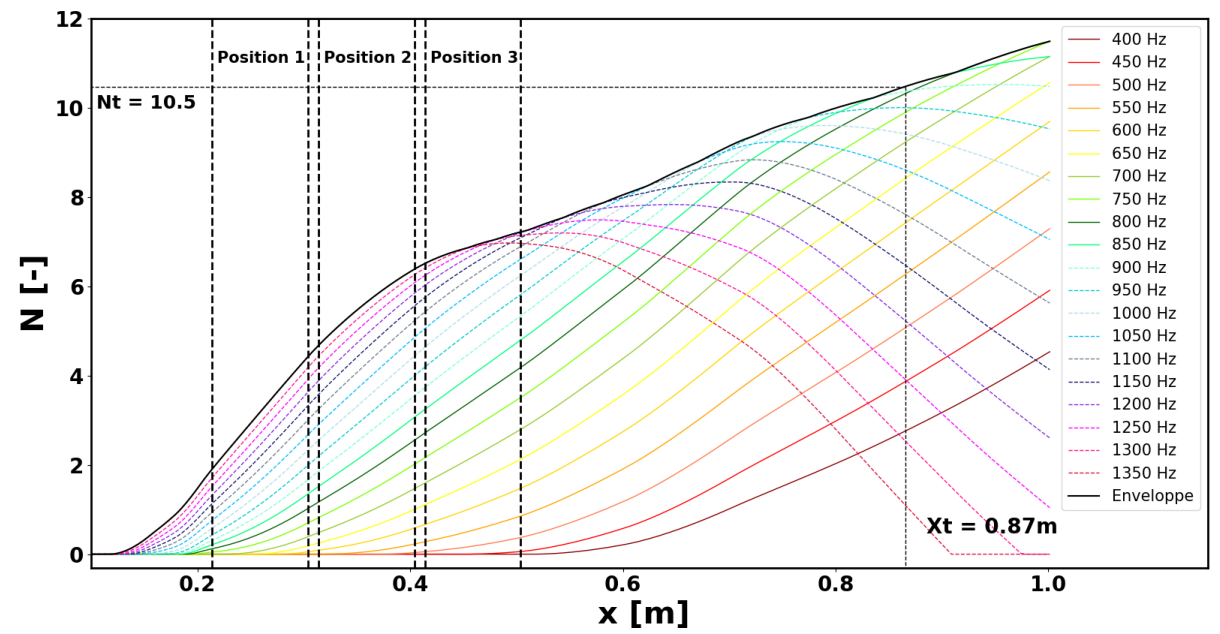

Fig. 9 Evolution of $\mathrm{N}$-factor along the flat plate $-\mathrm{Re}=3.5 \times 10^{6} \mathrm{~m}^{-1}$

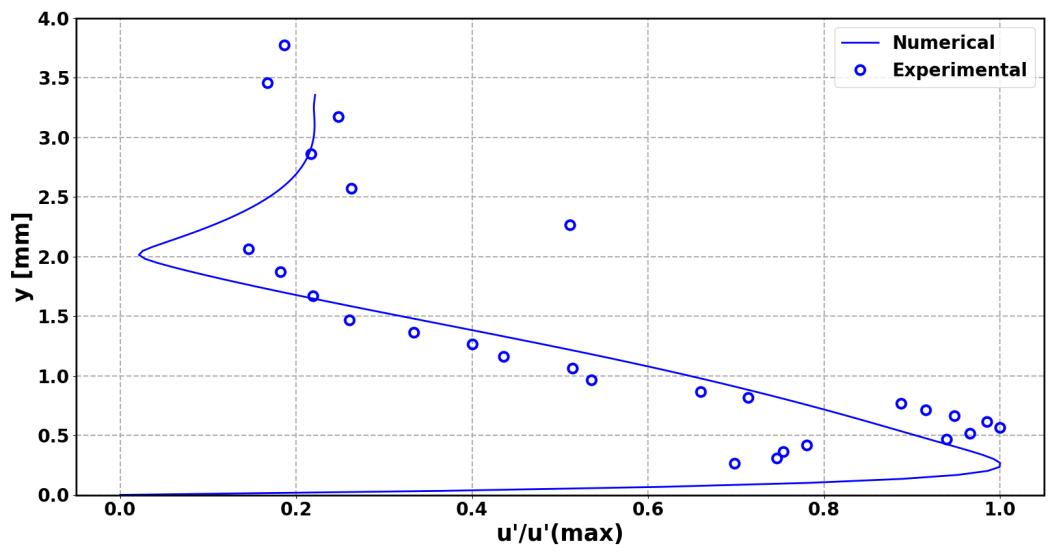

Fig. 10 Comparison of a numerical $(750 \mathrm{~Hz})$ and experimental $(730-770 \mathrm{~Hz})$ nondimensionalized TS wave $(\operatorname{Re}$ $=3.5 * 10^{6} \mathrm{~m}^{-1}, \mathrm{x}=870 \mathrm{~mm}$ )

\section{Results and discussion}

\section{A. Effect of roughness on mean velocity profile}

For every rough insert, wall-normal investigations were performed approximately every $100 \mathrm{~mm}$ in the streamwise direction starting from above the insert. The resultant mean velocity profiles are compared with the smooth case for 'position 1' (figure 12) and 'position 2' ( figure 13) in order to bring to light a potential effect of the surface roughness. A change in the mean velocity profile would result in a modification of the linear stability and thus a higher amplification than for the smooth case.

\section{B. Effect of roughness on transition location}

For 'position 3' case, the transition location has been determined for the three unit Reynolds numbers tested in the section $\mathrm{V}$. For 'position 1' and 'position 2' cases, performed later, the results during the experiments showed the necessity of acquiring results for more different Reynolds numbers. For each data point (i.e for a given position of surface roughness and a given unit Reynolds number), several data are obtained from either experimental or numerical 


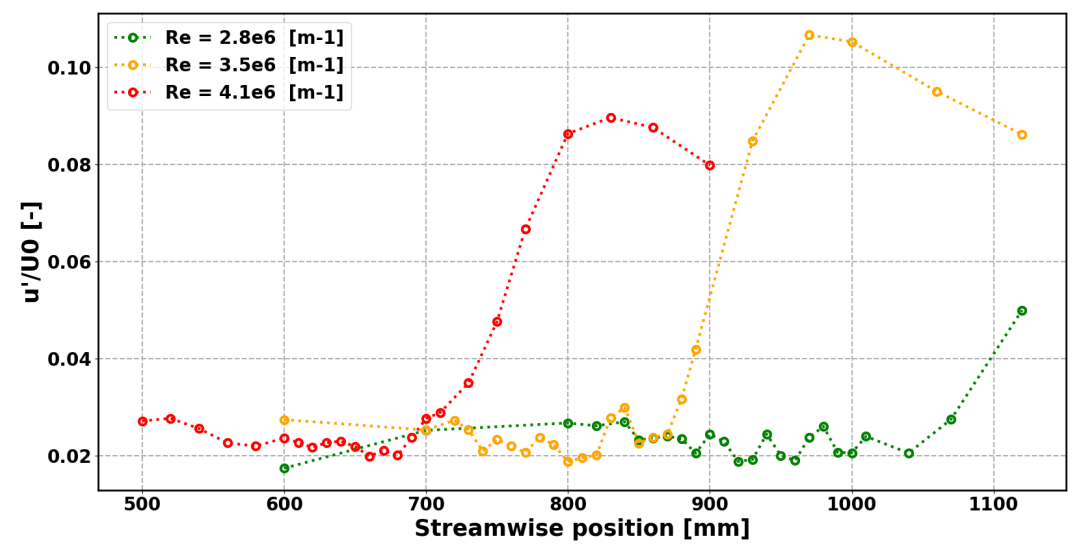

Fig. 11 Streamwise measurements of fluctuating velocity nondimensionalized $\frac{u^{\prime}}{U_{0}}$

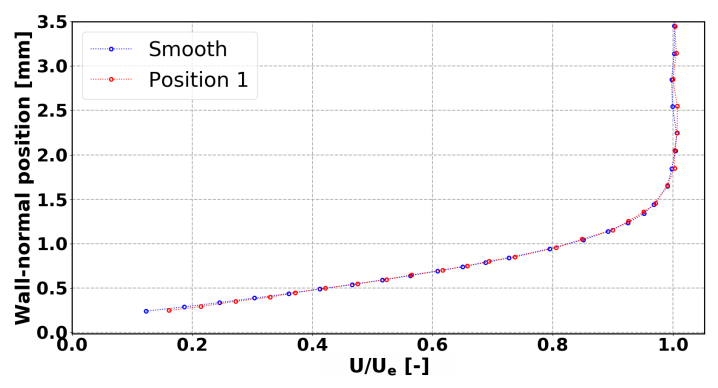

(a) $\operatorname{Re}=2.810^{6} \mathrm{~m}^{-1}, \mathrm{x}=280 \mathrm{~mm}$ (above roughness)

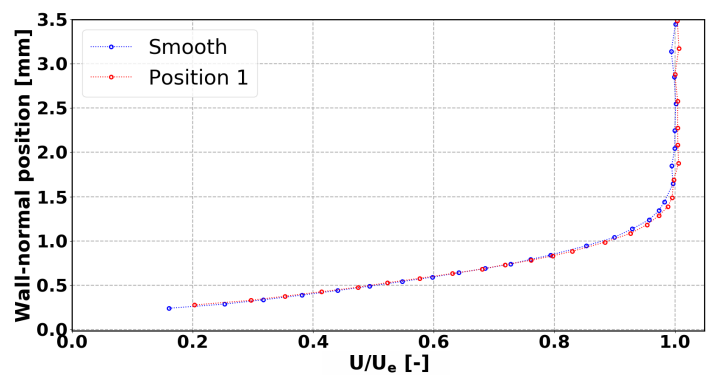

(c) $\operatorname{Re}=3.510^{6} \mathrm{~m}^{-1}, \mathrm{x}=280 \mathrm{~mm}$ (above roughness)

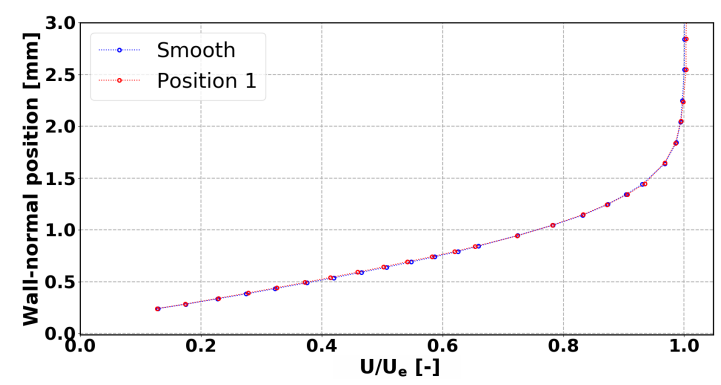

(b) $\operatorname{Re}=2.810^{6} \mathrm{~m}^{-1}, \mathrm{x}=360 \mathrm{~mm}$ (downstream roughness)

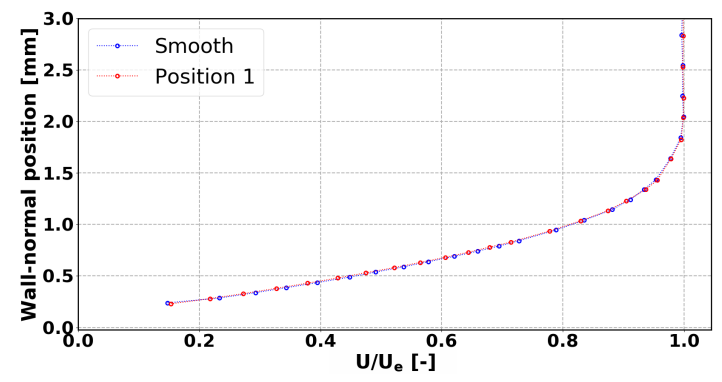

(d) $\operatorname{Re}=3.510^{6} \mathrm{~m}^{-1}, \mathrm{x}=360 \mathrm{~mm}$ (downstream roughness)

Fig. 12 Comparisons of mean velocity profiles between 'smooth' and 'position 1' cases

investigations: transition location and corresponding critical unit Reynolds number of transition $R e_{x_{T}}=\frac{U_{0} x_{T}}{v}$ and

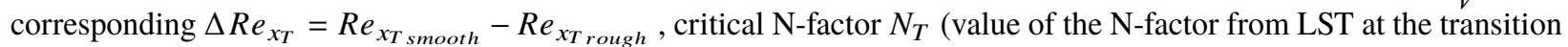
location) and corresponding $\Delta N_{T}=N_{T_{\text {smooth }}}-N_{T_{\text {rough }}}$, non-dimensionalized mean roughness $R a / \delta 1$ (the $\delta 1$ taken is the mean value of $\delta 1$ at the upstream and downstream edges of the rough insert) and the critical TS frequencies according to experiments and LST $F_{\text {exp }}$ and $F_{L S T}$. All the results are shown in tables 4.5 , and 6 for the three positions of the rough insert and the evolutions of $R_{x_{T}}, \Delta R_{x_{T}}$ and $\Delta N_{T}$ against the non-dimensionalized roughness are drawn in the figure 14 $\Delta N_{T}$ have to be considered with much care since this approach is relevant only if the surface roughness modify the amplification of existing instabilities and not if the receptivity process is changed (see next section). To help the understanding of the phenomena involved, LST computations and PSD of u' for some particular cases are shown 


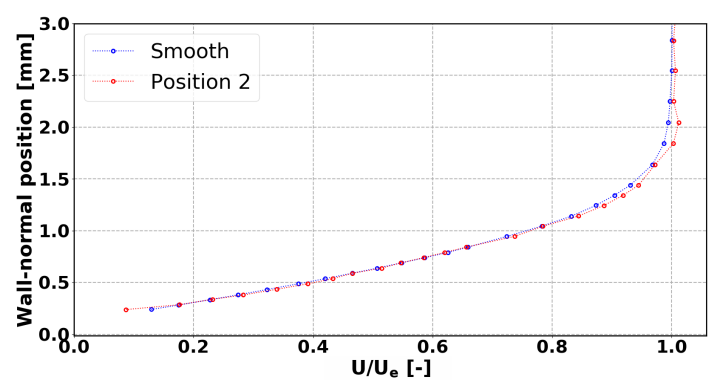

(a) $\operatorname{Re}=2.810^{6} \mathrm{~m}^{-1}, \mathrm{x}=360 \mathrm{~mm}$ (above roughness)

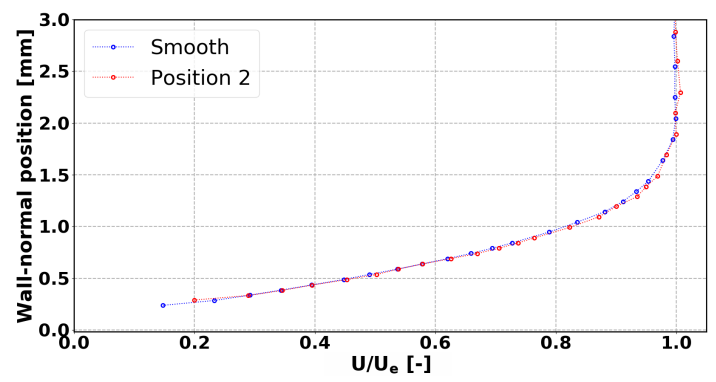

(c) $\operatorname{Re}=3.510^{6} \mathrm{~m}^{-1}, \mathrm{x}=360 \mathrm{~mm}$ (above roughness)

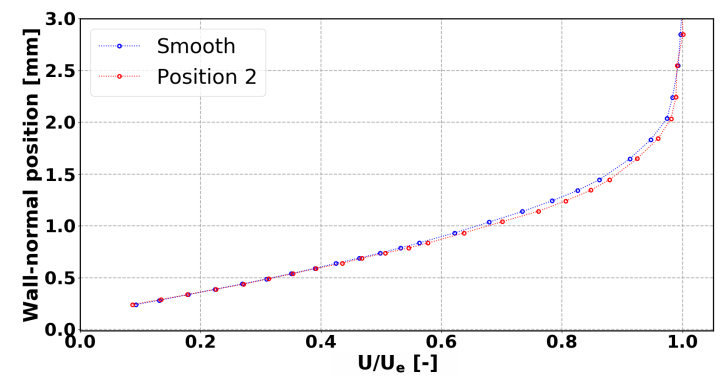

(b) $\operatorname{Re}=2.810^{6} \mathrm{~m}^{-1}, x=460 \mathrm{~mm}$ (downstream roughness)

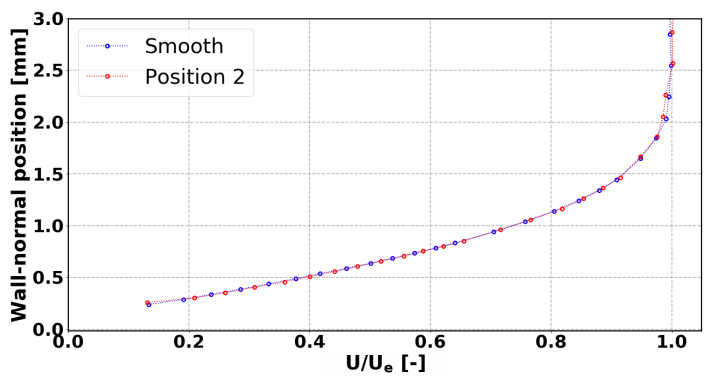

(d) $\operatorname{Re}=3.510^{6} \mathrm{~m}^{-1}, x=460 \mathrm{~mm}$ (downstream roughness)

Fig. 13 Comparisons of mean velocity profiles between 'smooth' and 'position 2' cases

figure 15, 16, 9,17 and 18 .

\begin{tabular}{|c|c|c|c|c|c|c|c|c|}
\hline$R e_{0}\left({\left.\mathrm{x} 10^{-6}\right)}^{-6}\right.$ & $x_{T}$ & $R e_{x_{T}}\left(\mathrm{x} \mathrm{10^{-6 } )}\right.$ & $\Delta R e_{x_{T}}\left(\mathrm{x} \mathrm{10}^{-6}\right)$ & $N_{T}$ & $\Delta N_{T}$ & $R a / \delta 1$ & $F_{\text {exp }}[\mathrm{Hz}]$ & $F_{L S T}[\mathrm{~Hz}]$ \\
\hline 1.9 & 1100 & 2.09 & 0.81 & 8.5 & 1.9 & 0.097 & $/$ & $/$ \\
\hline 2.1 & 1030 & 2.16 & 0.84 & 8.5 & 1.9 & 0102 & 300 & 400 \\
\hline 2.3 & 880 & 2.02 & 0.98 & 8 & 2.4 & 0.106 & 400 & 500 \\
\hline 2.8 & 770 & 2.16 & 0.84 & 8.4 & 2 & 1.117 & 550 & 700 \\
\hline 3.1 & 710 & 2.20 & 0.80 & 8.5 & 1.9 & 0.123 & $/$ & 850 \\
\hline 3.5 & 560 & 1.96 & 1.04 & 7.7 & 2.7 & 0.131 & $/$ & 1150 \\
\hline 3.8 & 430 & 1.63 & 1.37 & 7.1 & 3.3 & 0.136 & $/$ & 1500 \\
\hline 4.1 & 370 & 1.52 & 1.48 & 6.8 & 3.6 & 0.140 & 1900 & 1850 \\
\hline 4.3 & 340 & 1.46 & 1.54 & 6.6 & 3.8 & 0.144 & 2050 & 1800 \\
\hline
\end{tabular}

Table 4 Results for the rough insert in position 1 


\begin{tabular}{|c|c|c|c|c|c|c|c|c|}
\hline$R e_{0}\left(\times 10^{-6}\right)$ & $x_{T}$ & $R e_{x_{T}}\left(\mathrm{x} \mathrm{10}^{-6}\right)$ & $\Delta R e_{x_{T}}\left(\mathrm{x} \mathrm{10}^{-6}\right)$ & $N_{T}$ & $\Delta N_{T}$ & $R a / \delta 1$ & $F_{\text {exp }}[\mathrm{Hz}]$ & $F_{L S T}[\mathrm{~Hz}]$ \\
\hline 1.9 & 1100 & 2.09 & 0.91 & 8.5 & 1.9 & 0.089 & 310 & $/$ \\
\hline 2.1 & 1030 & 2.16 & 0.84 & 8.4 & 2 & 0.094 & 330 & 400 \\
\hline 2.3 & 920 & 2.12 & 0.88 & 8.2 & 2.2 & 0.098 & 420 & 500 \\
\hline 2.8 & 870 & 2.43 & 0.57 & 9 & 1.4 & 0.108 & 550 & 650 \\
\hline 3.1 & 820 & 2.54 & 0.46 & 9.3 & 1.1 & 0.114 & $/$ & 750 \\
\hline 3.5 & 760 & 2.66 & 0.34 & 9.7 & 0.7 & 0.121 & $/$ & 950 \\
\hline 3.8 & 670 & 2.55 & 0.45 & 9.4 & 1 & 0.125 & $/$ & 1150 \\
\hline 4.1 & 600 & 2.46 & 0.54 & 8.9 & 1.5 & 0.129 & $/$ & 1350 \\
\hline 4.3 & 450 & 1.93 & 1.07 & 7.8 & 2.6 & 0.133 & 1800 & 1750 \\
\hline
\end{tabular}

Table 5 Results for the rough insert in position 2

\begin{tabular}{|c|c|c|c|c|c|c|c|c|}
\hline$R e_{0}\left(\mathrm{x} \mathrm{10} 0^{-6}\right)$ & $x_{T}$ & $R e_{x_{T}}\left(\mathrm{x} \mathrm{10}^{-6}\right)$ & $\Delta R e_{x_{T}}\left(\mathrm{x} \mathrm{10^{-6 } )}\right.$ & $N_{T}$ & $\Delta N_{T}$ & $R a / \delta 1$ & $F_{\text {exp }}[\mathrm{Hz}]$ & $F_{L S T}[\mathrm{~Hz}]$ \\
\hline 2.8 & 970 & 100 & 2.72 & 0.28 & 9.7 & 0.086 & 500 & 600 \\
\hline 3.5 & 720 & 150 & 2.52 & 0.48 & 9.4 & 0.096 & 1000 & 1000 \\
\hline 4.1 & 580 & 130 & 2.38 & 0.06 & 8.8 & 0.103 & 1350 & 1500 \\
\hline
\end{tabular}

Table 6 Results for the rough insert in position 3

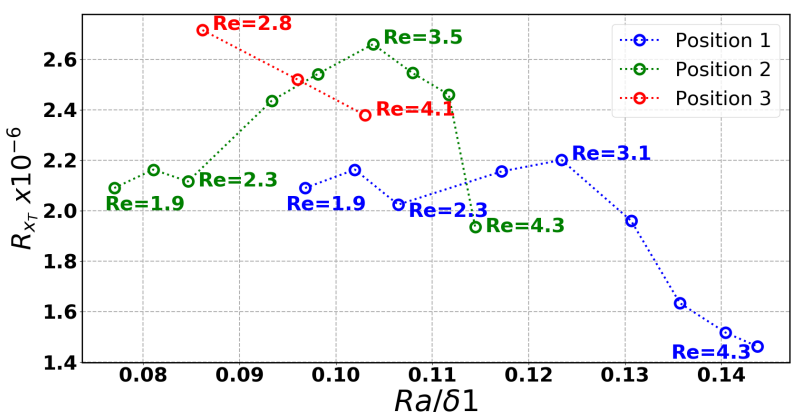

(a) $R_{x_{T}}$

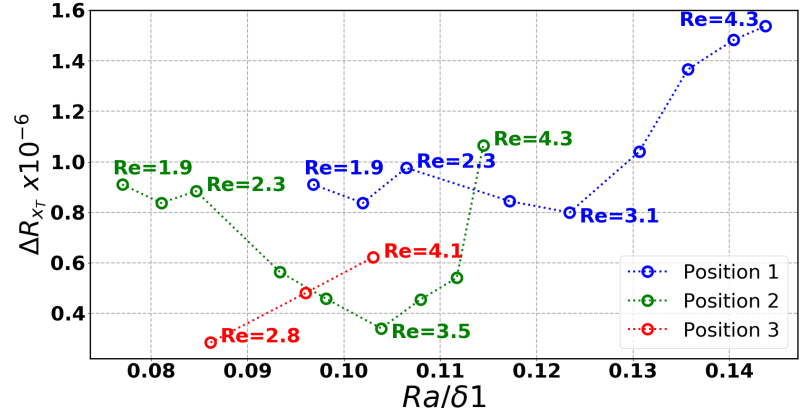

(b) $\Delta R_{x_{T}}$

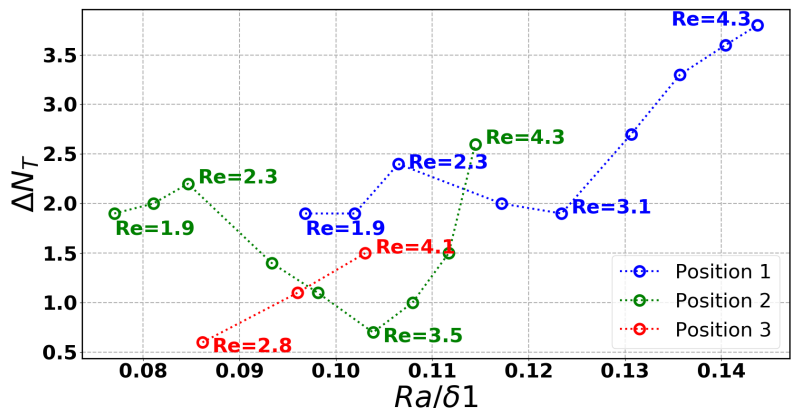

(c) $\Delta N$

Fig. 14 Evolutions of $R_{x_{T}}, \Delta R_{x_{T}}$ and $\Delta N$ against $R a / \delta 1$. Reynolds number rises from left to right. 


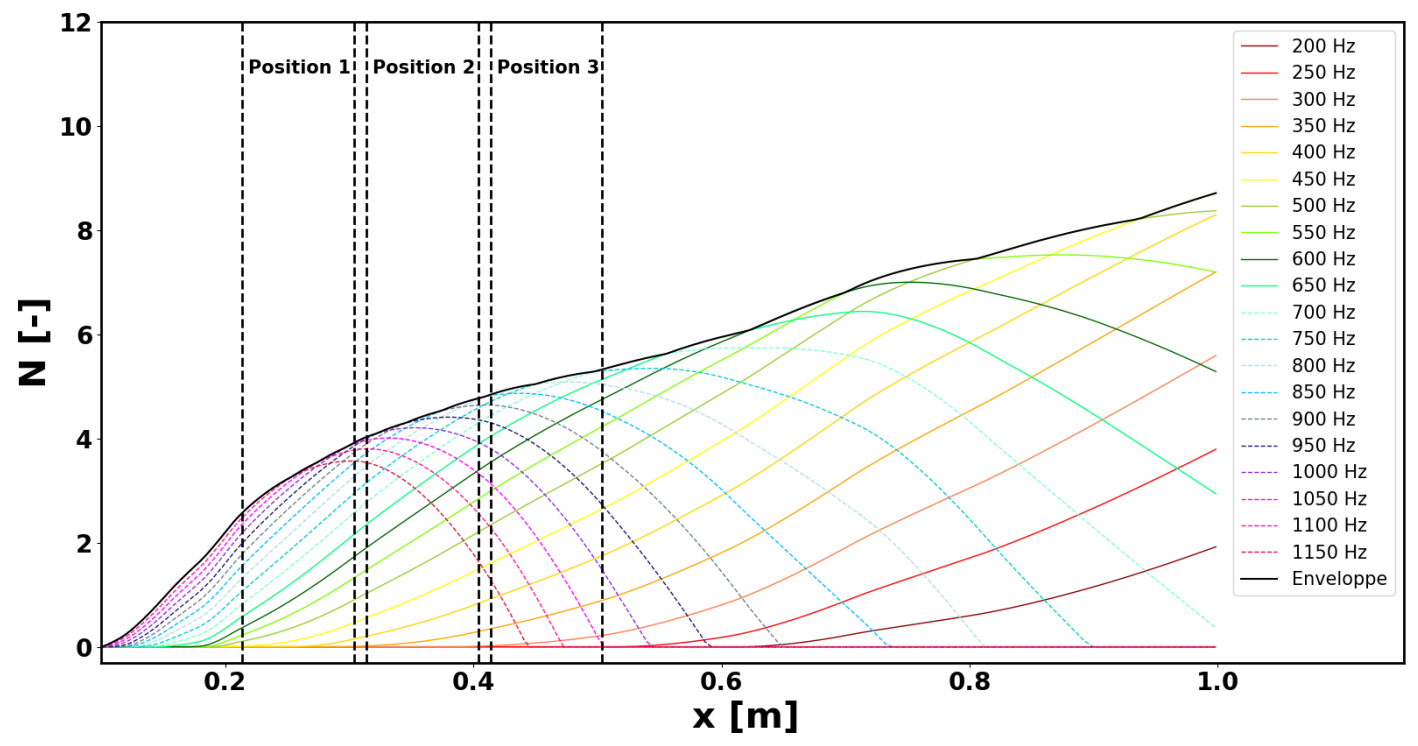

Fig. 15 LST for Re $=2.3 \times 10^{6} \mathrm{~m}^{-1}$

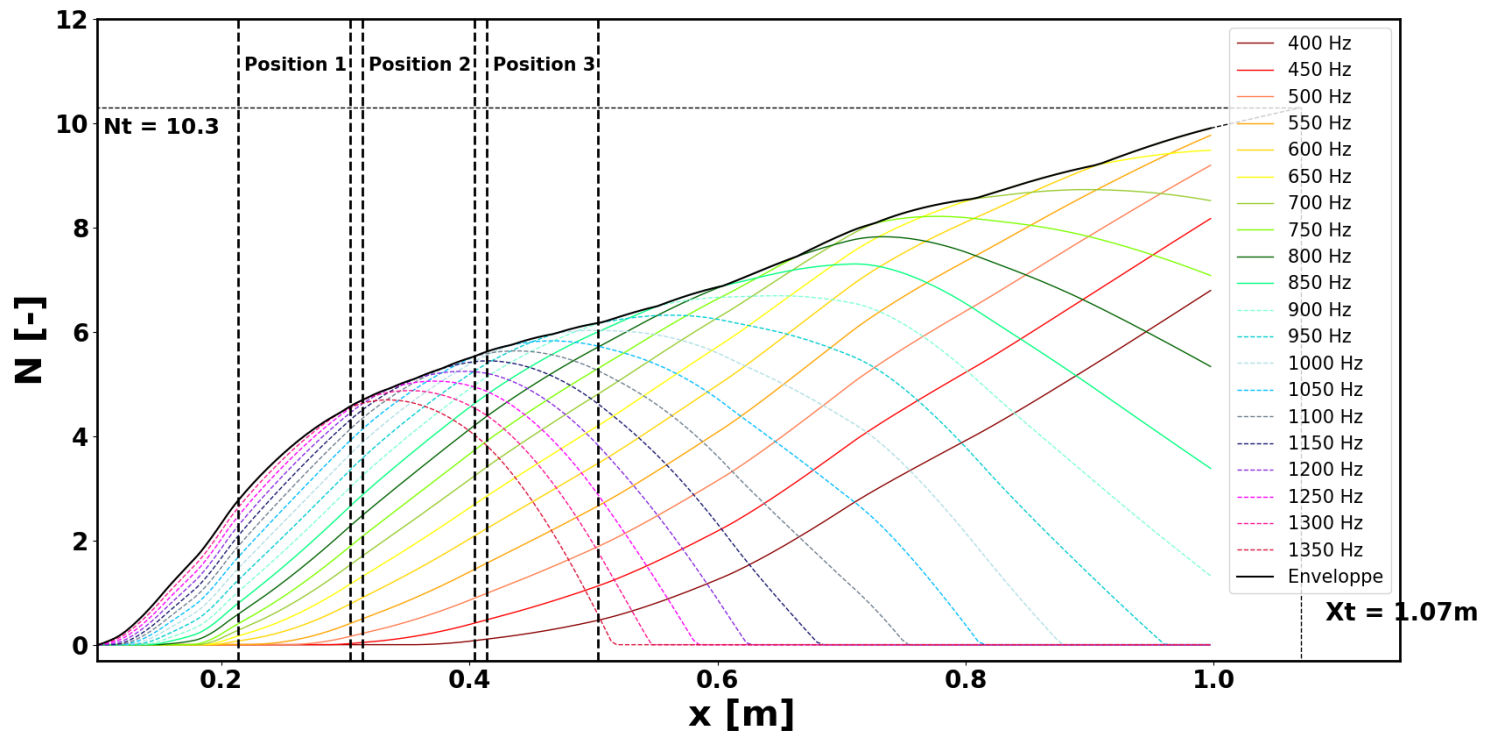

Fig. 16 LST for Re $=2.8 \times 10^{6} \mathrm{~m}^{-1}$ 


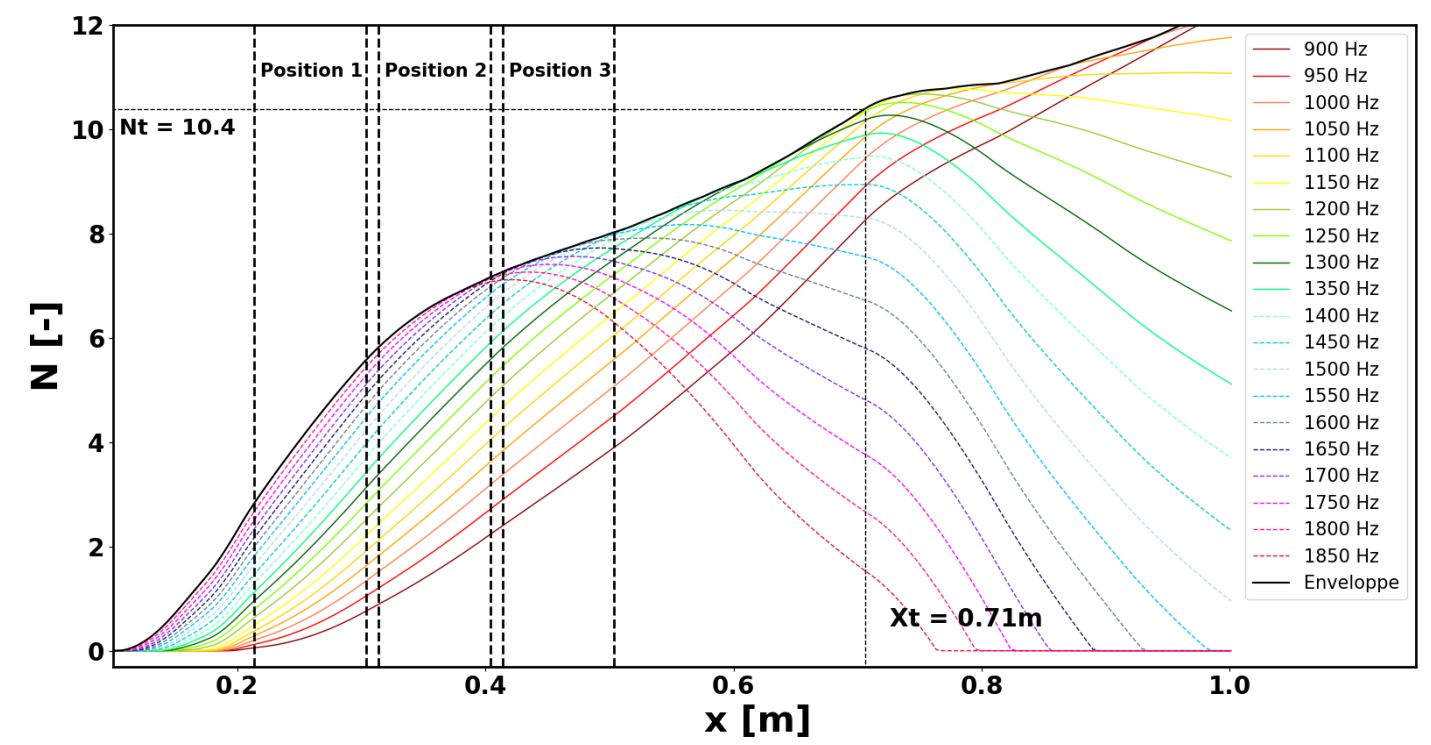

Fig. 17 LST for $\operatorname{Re}=4.1 \times 10^{6} \mathrm{~m}^{-1}$

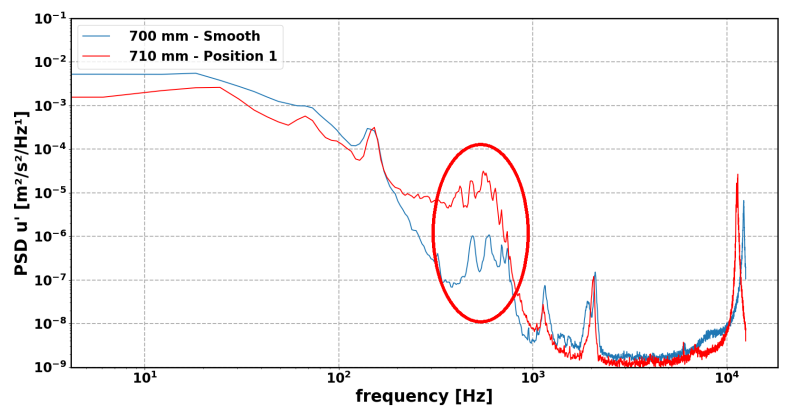

(a) $\operatorname{Re}=2.8 \times 10^{6} \mathrm{~m}^{-1}, \mathrm{x}=710 \mathrm{~mm}, \mathrm{z}=600 \mu \mathrm{m}$

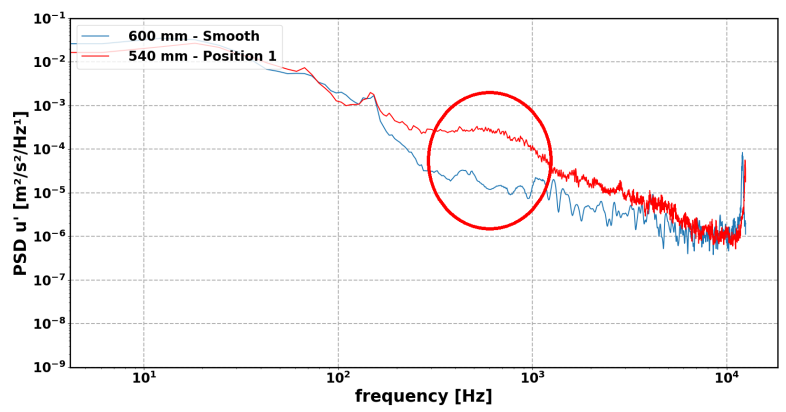

(b) $\operatorname{Re}=3.5 \times 10^{6} \mathrm{~m}^{-1}, \mathrm{x}=540 \mathrm{~mm}, \mathrm{z}=600 \mu \mathrm{m}$

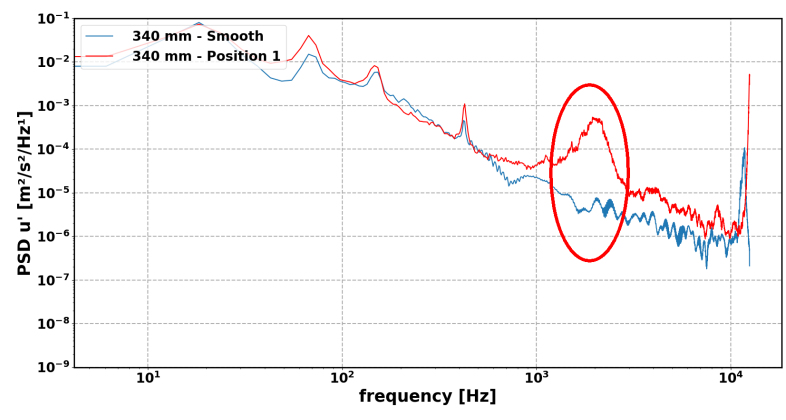

(c) $\operatorname{Re}=4.3 \times 10^{6} \mathrm{~m}^{-1}, \mathrm{x}=340 \mathrm{~mm}, \mathrm{z}=600 \mu \mathrm{m}$

Fig. 18 Comparisons of PSD for 'smooth' and 'Position 1' cases 


\section{Discussions}

Among all the mean velocity profiles measurements, no dramatic distortion of the boundary layer was observed. Very little differences between the smooth and the rough cases can be seen in figures 12 and 13 but they are not really significant. This is consistent with the experiments of Jeong [8] where no clear distortion of a boundary layer due to surface roughness was visible. Be that as it may, the results obtained here do not allow to conclude whether amplification is affected by roughness since very little distortion of the boundary layer can have dramatic effect on the amplification, as shown by Methel [12] who found nearly no effect of suction on the boundary layer profile whereas the influence on amplification was clearly demonstrated. More investigations, especially in the near-wall region where the influence of the surface roughness could be the most important, will be necessary to conclude.

The transition location was expected to be all the more shifted upstream as the ratio $R a / \delta 1$ is high, but it can be observed from the cases 'position 1' and 'position 2' of the figure 14 that the evolution is not monotonous. Observing the 'position 1' (respectively 'position 2') curves on these three figures, it can be seen that between $\mathrm{Re}=2.310^{6} \mathrm{~m}^{-1}$ (respectively $\operatorname{Re}=2.310^{6} \mathrm{~m}^{-1}$ ) and $\operatorname{Re}=3.110^{6} \mathrm{~m}^{-1}$ (respectively $\operatorname{Re}=3.510^{6} \mathrm{~m}^{-1}$ ), the critical Reynolds number decreases while the Reynolds number rises (and then $R a / \delta 1$ increases too) .

At the moment, there is no detailed explanation for this phenomenon but several possibilities can be considered.The inserts used have academical square roughness. Contrary to real random surface roughness, it could be possible that this particular shape tends to stabilize or destabilize some particular TS waves, depending on their wavelengths. This has to be considered but there is currently no clue about the phenomenon which could be involved. Moreover, the length of the squares of which the roughness is made (about $1 \mathrm{~mm}$ ) is far more little than the wavelengths of the TS which trigger the transition (about $2 \mathrm{~cm}$, depending on the location, Reynolds number and frequency). An experiment could allow to determine whether this is the good explanation: the same configuration has to be tested but with a roughness which is really random (with sand paper for instance) or quasi-random (3D printed with a specific algorithm).

There also could be a competition between two phenomena: receptivity and amplification of the TS waves. In the figures 15, 16 , 9 and 17 are displayed the LST results over the flat plate for the smooth case at $\operatorname{Re}=2.3,2.8,3.5$ and 4.1 $\mathrm{x} 10^{6} \mathrm{~m}^{-1}$. If we consider for a given frequency that the receptivity zone ends where the amplification begins, it can be seen for $\mathrm{Re}=2.3 \times 10^{6} \mathrm{~m}^{-1}$ that the most amplified frequency at the transition (500 Hz for 'position 1' and 'position 2' according to LST) is really close to the beginning of the roughness. Moreover, really close frequencies ( $450 \mathrm{~Hz}$ for 'position 1' and $300 \mathrm{~Hz}$ for 'position 2') has the end of their receptivity zone above the rough insert. When the Reynolds number rises, the receptivity zone of the most amplified frequencies ends more upstream of the rough insert. This could explain the shapes of the curves obtained. Indeed, for 'position 1' case, the receptivity could be the phenomenon the more altered by roughness in the range $\operatorname{Re}=[0,2.3] 10^{6} \mathrm{~m}^{-1}$ and amplification above $\operatorname{Re}=3.1 \times 10^{6} \mathrm{~m}^{-1}$. In the range $\operatorname{Re}=[2.3,3.1] 10^{6} \mathrm{~m}^{-1}$ the influence of receptivity decreases more than amplification's one increases.

Spectral analyses may confirm this. Indeed, looking at the figure 18 and the frequencies in table 4 and 5 , several phenomenon can be observed. For 'low' Reynolds numbers, the frequencies measured seem more little than what is predicted by LST. For 'middle' ones, the PSD does not allow to determine the frequency because the TS bump in the spectrum is too large and flattened. For 'high' Reynolds, this TS signal is back and the agreement with LST is quite good. This could be consistent with a higher receptivity due to roughness. Indeed, for 'low' Reynolds numbers, the transition could be driven by lower frequencies than for the smooth case due to surface roughness increase in their receptivity zone. This would be consistent with the TS bumps which starts for lower frequencies for the rough case. For 'middle' Reynolds numbers, their could be a balance between low frequencies which have their receptivity increased and higher frequencies which should have triggered the transition because of a higher amplification. This would explain the smoothed and elongated bump instead of the classic TS signal. And for high Reynolds numbers, this signal is visible because the most amplified TS has a frequency which is much higher than those of which the receptivity is affected by roughness.

\section{Conclusion}

The present work introduced a methodology to study the influence of surface roughness on the laminar-turbulent transition driven by TS waves of a boundary layer. To do so, a flat plate was machined to create a large rectangular recess in which can be put three exchangeable inserts which can be either smooth (metallic) or rough (3D printed). First measurements at different Reynolds numbers with smooth inserts showed a good agreement with numerical values obtained with ONERA's boundary layer and LST in-house codes, providing a reference 'smooth' case to compare with. Then, the same roughness surface was then tested at three different streamwise positions for different Reynolds numbers.

Really little changes in the mean velocity profile were observed over the flat plate above and/or downstream the 
rough inserts when changing the surface roughness. Nevertheless, the differences of mean velocity profiles between smooth and rough experiments are too little to conclude whether there is a significant effect of the roughness.

Surface roughness was found out to shift the transition location upstream. However, the evolution of this shift against roughness was more complex than expected. Indeed, instead of rising continuously with the ratio $R_{a} / \delta 1$, the shift of $\Delta N_{T}=N_{T_{\text {smooth }}}-N_{T_{\text {rough }}}$ decreases and re-rises around a particular value. This could be due to the fact that the roughness tested is very regular and tends to be less destabilizing for some TS waves depending on their wavelength. A more probable explanation would be the fact that the roughness changes the receptivity for low frequency instabilities. Then, their would be a competition between receptivity, which has important influence for low Reynolds numbers and frequencies, and amplification for higher Reynolds numbers and frequencies.

\section{Appendix}

\section{A. Roughness parameters}

\section{Skewness - Rsk}

Skewness gives an information on the asymmetry of the profile. Contrary to $R a$ and $R q$, it is not an information about the height, but about the shape of the roughness. Positive skewness corresponds to a profile with pikes whereas a negative skewness is for a surface with valleys.

$$
R_{s k}=\frac{1}{L R_{q}^{3}} \int_{0}^{L} r^{3}(x) \mathrm{d} x
$$

The discretized expression is the following:

$$
R_{s k}=\frac{1}{N R_{q}^{3}} \sum_{i=1}^{N} r_{i}^{3}
$$

\section{Kurtosis - Rku}

The kurtosis is the distribution of the heights. The distribution is rather flat if $R_{k u}$ is lower than three, while it is peaky if it is higher.

$$
R_{k u}=\frac{1}{L R_{q}^{4}} \int_{0}^{L} r^{3}(x) \mathrm{d} x
$$

The discretized expression is the following:

$$
R_{k u}=\frac{1}{N R_{q}^{4}} \sum_{i=1}^{N} r_{i}^{4}
$$

\section{Measurement of statistical roughness values}

Scanning a surface with the Gocator 2320 provides a matrix of heights. A line of this matrix is made of the heights measured with one scan with the Gocator's laser, the matrix is then obtained by doing several scans by moving the laser along the surface. An algorithm was developped to calculate the statistical values thanks to discretized expressions described previously. To control the statistical values, three different calculations are made from this matrix of heights:

- "Line by line": statistical roughness values are calculated for each line of the matrix, and then their mean values

- "Column by column": statistical roughness values are calculated for each column of the matrix, and then their mean values

- "Whole surface": statistical roughness values are calculated using the mean height of the whole surface

\section{References}

[1] Morkovin, M., “Transition in open flow systems-a reassessment," Bull. Am. Phys. Soc., Vol. 39, 1994, p. 1882. 


\begin{tabular}{|c|c|c|c|c|}
\hline & $\mathrm{Ra}[\mu \mathrm{m}]$ & $\mathrm{Rq}[\mu \mathrm{m}]$ & $\mathrm{R}_{\mathrm{sk}}[-]$ & $\mathrm{R}_{\mathrm{ku}}[-]$ \\
\hline Line bye line & 56 & 63 & 0.097 & 1.99 \\
\hline Whole surface & 56 & 64 & 0.068 & 1.98 \\
\hline Column by column & 56 & 64 & 0.069 & 1.97 \\
\hline
\end{tabular}

Table 7 Example of calculation of roughness parameters

[2] Squire, H. B., "On the stability for three-dimensional disturbances of viscous fluid flow between parallel walls," Proceedings of the Royal Society of London. Series A, Containing Papers of a Mathematical and Physical Character, Vol. 142, No. 847, 1933, pp. 621-628.

[3] Arnal, D., Perraud, J., and Séraudie, A., "Attachment line and surface imperfection problems," Advances in Laminar-Turbulent Transition Modeling, RTO-EN-AVT-151-09, 2008, pp. 1-20.

[4] Corke, T., Bar-Sever, A., and Morkovin, M., "Experiments on transition enhancement by distributed roughness," Physics of Fluids, Vol. 29, No. 10, 1986, pp. 3199-3213.

[5] Von Doenhoff, A. E., and Braslow, A. L., "The effect of distributed surface roughness on laminar flow," Boundary layer and flow control, Elsevier, 1961, pp. 657-681.

[6] Braslow, A. L., and Knox, E. C., "Simplified method for determination of critical height of distributed roughness particles for boundary-layer transition at Mach numbers from 0 to 5," 1958.

[7] Von Doenhoff, A. E., and Horton, E. A., "A low-speed experimental investigation of the effect of a sandpaper type of roughness on boundary-layer transition," 1958.

[8] Jeong, H., Lee, S. W., and Song, S. J., "Measurement of Transitional Surface Roughness Effects on Flat-Plate Boundary Layer Transition," Journal of Fluids Engineering, Vol. 141, No. 7, 2019.

[9] Roberts, S., and Yaras, M., "Boundary-layer transition affected by surface roughness and free-stream turbulence," Journal of fluids engineering, Vol. 127, No. 3, 2005, pp. 449-457.

[10] Crouch, J., and Ng, L., "Variable N-factor method for transition prediction in three-dimensional boundary layers," AIAA journal, Vol. 38, No. 2, 2000, pp. 211-216.

[11] Crouch, J., Ng, L., Kachanov, Y., Borodulin, V., and Ivanov, A., "Influence of surface roughness and free-stream turbulence on crossflow-instability transition," Procedia IUTAM, Vol. 14, 2015, pp. 295-302.

[12] Methel, J., Vermeersch, O., Forte, M., and Casalis, G., "Experimental characterization of the laminar-turbulent transition of a sucked boundary layer due to surface defects in a two-dimensional incompressible flow," 2018 Flow Control Conference, 2018, p. 3214. 